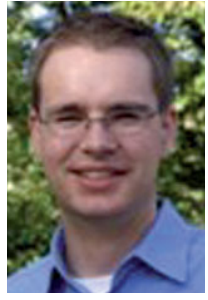

Nico Jehmlich

2001-2006 Biologiestudium an der Universität Leipzig. 20062009 Promotion am HelmholtzZentrum für Umweltforschung (UFZ) Leipzig, Department

Proteomik bei PD Dr. von Bergen. Seit 2009 Postdoc an der Universität Greifswald. 2010 Forschungsaufenthalt Vanderbilt Universität Nashville, TN, USA, Department Biochemie.

Bakterien sind unverzichtbar für bedeutende biogeochemische Stoffkreisläufe sowie biotechnologische und medizinische Anwendungen. Vor allem bakterielle Mischkulturen und bisher nicht kultivierbare Bakterienarten führen dabei einen Großteil der notwendigen Umsetzungen aus. Für die Charakterisierung mikrobieller Gemeinschaften aus Umwelthabitaten wurden mit Metagenom- und Metatranskriptomansätzen inzwischen kulturunabhängige Methoden auf genomischer und transkriptomischer Ebene entwickelt, die allerdings nur begrenzt Aussagen über die tatsächliche Aktivität, also die Proteinzusammensetzung und deren Funktionen erlauben.

Der Aufklärung der strukturellen Zusammensetzung und der metabolischen Funktion von Mikroorganismen in Gemeinschaften dient die Protein-SIP(protein-based stable iso-
VAAM-Promotionspreis 2011

\section{Protein-SIP zur Charakterisierung mikrobieller Gemeinschaften}

\author{
NICO JEHMLICH
}

INSTITUT FÜR GENETIK UND FUNKTIONELLE GENOMFORSCHUNG, UNIVERSITÄT

GREIFSWALD tope probing)-Methode, die wir am HelmholtzZentrum für Umweltforschung, Leipzig (UFZ) im Department Proteomik etablierten [1]. Grundlage dieser Methode ist die Verwendung von Kohlenstoff- und/oder Energiequellen, die teilweise oder vollständig mit stabilen Isotopen (meist ${ }^{13} \mathrm{C}$ oder ${ }^{15} \mathrm{~N}$ ) markiert werden (Abb. 1). Die metabolische Umsetzung des markierten Substrats und der Einbau in die Biomasse der Bakterien kann durch den quantitativen Einbau der Markierung in die Proteine bewertet werden, was eine Unterscheidung von Arten und deren spezifischer metabolischer Aktivität in einer mikrobiellen Gemeinschaft ermöglicht. Durch die Komplexität des Metaproteoms aus mikrobiellen Gemeinschaften ist die Anwendung verschiedener Vorfraktionierungstechniken vor der Massenspektroskopie unerlässlich. Durch

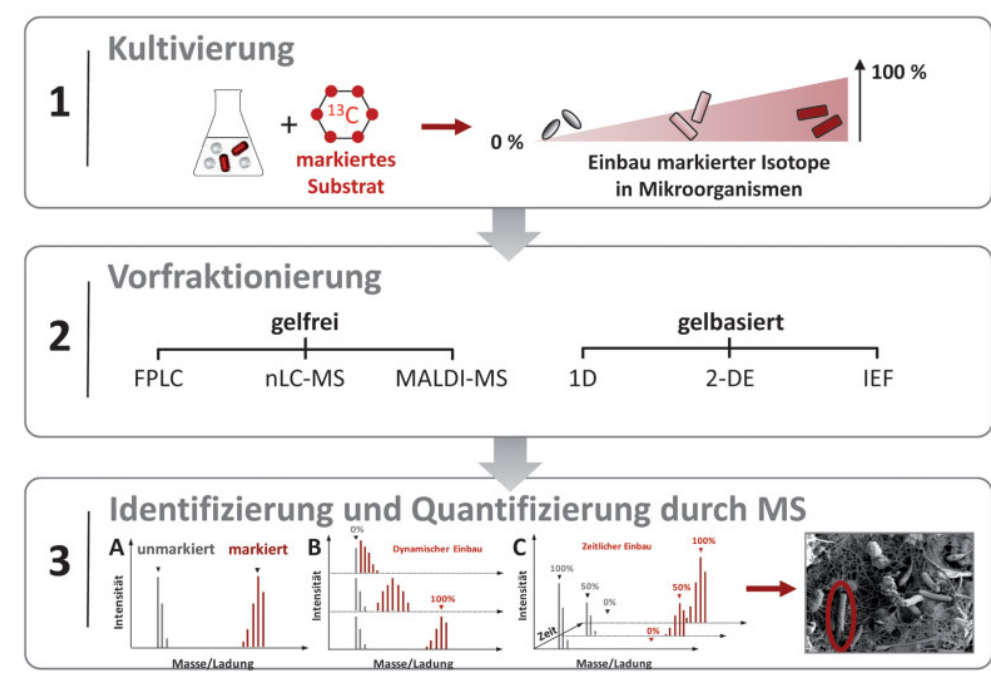

$\triangle$ Abb. 1: Protein-SIP-Methode. (1) Markiertes Substrat (z. B. ${ }^{13} \mathrm{C}$ oder $\left.{ }^{15} \mathrm{~N}\right)$ wird in die Kultur eingebracht und von Bakterien umgesetzt. (2) Vorfraktionierung der Proteine. Exemplarisch für die gelfreien Techniken: fast-Protein-Flüssigkeitschromatografie (FPLC), nano-Flüssigkeitschromatografie (nLC) sowie Matrix-unterstützte Laser-Desorption/Ionisation (MALDI) gekoppelt mit Massenspektrometrie (MS). Gelbasierte Techniken: ein- und zweidimensionale Gelelektrophorese (1D und 2-DE) und isoelektrische Fokussierung (IEF). (3) Identifizierung und Quantifizierung der Proteine sowie Bestimmung des Einbaus stabiler Isotope erfolgen durch massenspektrometrische Messungen. In Abhängigkeit vom Grad der Markierung des Substrats und des Verhältnisses zwischen markiertem und unmarkiertem Substrat ist ein dynamischer Einbau stabiler Isotope in die Peptide erkennbar. Zeitliche Verlaufsmessungen erlauben die Quantifizierung von Proteinsyntheseraten und -abbauraten nach Substratwechselexperimenten. Die Analysen führen zur Identifizierung des aktiven Substrat-abbauenden Organismus in einer mikrobiellen Gemeinschaft. die hohe Massengenauigkeit der Massenspektrometer und der immer größer werdenden Genomdatenbank auf dem Gebiet der mikrobiellen Ökologie kann ein Peptid, und damit das dazugehörige Protein, identifiziert werden. Zusätzlich lässt sich aus dem Massenspektrum der Einbau der stabilen Isotope - vorwiegend auf Peptidebene - quantitativ bestimmen [2].

Protein-SIP repräsentiert somit einen neuen proteomischen Ansatz zur Charakterisierung von mikrobiellen Gemeinschaften aus Umwelthabitaten. Eine weitere Anwendung von Protein-SIP ist die Quantifizierung von Proteinneusynthese- und Proteinabbauraten nach Substratwechsel [3]. Darauf basierende Anwendungen können zur Aufklärung wichtiger ökologischer Fragen, wie der Charakterisierung von Schlüsselorganismen, die an wichtigen geobiochemischen Prozessen beteiligt sind, beitragen.

\section{Literatur}

[1] Jehmlich N, Schmidt F, Taubert M et al. (2010) Proteinbased stable isotope probing. Nat Protoc 5:1957-1966 [2] Jehmlich N, Fetzer I, Seifert J et al. (2010) Decimal place slope, a fast and precise method for quantifying $13 \mathrm{C}$ incorporation levels for detecting the metabolic activity of microbial species. Mol Cell Proteomics 9:1221-1227

[3] Taubert M, Jehmlich N, Vogt C et al. (2011) Time resolved protein-based stable isotope probing (Protein-SIP) analysis allows quantification of induced proteins in substrate shift experiments. Proteomics (im Druck)

\section{Korrespondenzadresse:}

Dr. Nico Jehmlich

Abteilung Funktionelle Genomforschung Interfakultäres Institut für Genetik und Funktionelle Genomforschung

Ernst-Moritz-Arndt-Universität Greifswald Friedrich-Ludwig-Jahn-Straße 15a

D-17487 Greifswald

Tel.: 03834-86-22631

Fax: 03834-86-795872

nico.jehmlich@uni-greifswald.de

Die beiden weiteren Preisträger stellen ihre Arbeiten in Heft 5/2011 vor.

Die VAAM dankt den Sponsoren der diesjährigen Promotionspreise: BASF SE, Sanofi-Aventis Deutschland, New England Biolabs $\mathrm{GmbH}$, Bayer Schering Pharma AG, Evonik Degussa GmbH 